Article

\title{
Intravaginal Devices and GNSS Collars with Satellite Communication to Detect Calving Events in Extensive Beef Production in Northern Australia
}

\author{
Christie Pearson*, Lucy Lush and Luciano A. González \\ Sydney Institute of Agriculture, School of Life and Environmental Science, Faculty of Sciences, \\ The University of Sydney, Camden, NSW 2570, Australia; llush@scottishwildlifetrust.org.uk (L.L.); \\ luciano.gonzalez@sydney.edu.au (L.A.G.) \\ * Correspondence: christie.pearson@sydney.edu.au
}

Received: 18 November 2020; Accepted: 1 December 2020; Published: 3 December 2020 updates

\begin{abstract}
Observing calves at birth may help to identify risk factors for, and reduce, calf loss in extensive beef systems. The objectives of this study were to: (1) evaluate two commercial satellite birth alert systems to enable the observation of newborn calves and (2) assess behavioral changes of cows around calving. Vaginal Implant Transmitters (VIT) paired with Global Navigation Satellite System (GNSS) collars were worn by 20 cows in Trial 1 and 10 cows in Trial 2 to identify birthing events. The VIT and GNSS collars contained a temperature sensor, accelerometer, and very high frequency (VHF) to communicate with a handheld tracker, and ultra-high frequency (UHF) for communication between the VIT and GNSS collar, which had two-way communication using Iridium satellites. A change (Brand 1) or drop (Brand 2) in temperature of more than $3{ }^{\circ} \mathrm{C}$ and inactivity triggered the VIT to communicate an expelled alert to the collar, which transmitted the birth alert information via Iridium (device ID, date, time and geolocation of the GNSS collar at expulsion). Cows and calves were tracked in the paddock following a birth alert to assess their health and status. Overall, true birth alerts occurred in only $27.6 \%$ of devices. Cows remained active on the day of calving travelling $5.54 \pm 4.11$ and $5.00 \pm 2.80 \mathrm{~km} /$ day compared to $6.45 \pm 2.79$ and $6.12 \pm 2.30 \mathrm{~km} / \mathrm{d}$ on days when calving did not occur for Trial 1 and 2, respectively (mean \pm SD). Average activity of the accelerometer $X$ - and $Y$-axis on calving day was reduced by $15 \%-20 \%$ compared to other days in Trial $1(p<0.05)$ but not in Trial $2(p>0.05)$. Results suggest that these two birth alert systems are not suitable for use in extensive systems and the further development of the technology is required. Cows in the current trials remained active on the day of, and after, calving, indicating that a faster, real-time alert system and communication protocol would be required to achieve the aim of finding newborn calves.
\end{abstract}

Keywords: vaginal implant tag; birth site; beef cattle; calving; remote sensing technology

\section{Introduction}

Offspring mortality is directly linked to the success of a species, so investigating reasons for mortality is of importance in any species where mortalities are occurring [1]. High mortality and low calf weaning rates have had the greatest impact on productivity in northern Australian beef cattle production [2]. Similarly to many animal species, data collected during birthing events and the first few days of life could provide critical information to understand factors contributing to such losses [3-7]. Calf mortality is seemingly high with 71 calves weaned for every 100 cows exposed to a bull in northern Australia, compared to $86 \%$ in southern Australian enterprises [8]. Calf mortalities are likely caused by a combination of factors including miss-mothering, wild dog predation, diseases and 
mustering practices, although the relative contribution of each risk factor has not been identified [2]. The lack of information is a result of the difficulties collecting data on newborn calves due to the remoteness, vegetation density, hilly terrain and large scale of the paddocks. For example, stocking rates in northern Australia are often as low as 1 animal per 20 hectares and paddock sizes can often be in excess of 120 square kilometers [9].

Calving alert devices and technologies to measure calving time and location have been used in deer, elk and bighorn sheep using vaginal implant transmitters (VIT) and GNSS collars with some success [4,6,10-14]. However, only 5\% of VIT devices deployed in wild elk resulted in the successful capture of an elk calf at birth, with more calves being found after visual surveillance was conducted [13]. In addition, pre-birth shedding of the VIT occurred in half of all cases, which was possibly caused by the size and shape of the implant in relation to the female $[6,10,15]$. Nevertheless, VIT allowed the collection of information close to the time of calving for the identification of potential risk factors for mortality [14]. Importantly, no studies have been published using satellite birth alert systems in cattle under extensive conditions. In contrast to wildlife, calving site is often not relevant in farmed cattle because of small areas (paddocks or barns), the timing of device placement can be controlled, and approximate calving due dates are known [11-14]. A study on a commercial beef enterprise in Japan used wireless vaginal temperature sensors to measure the drop in temperature with expulsion of the device inserted seven days prior to calving, reporting 625 true alerts out of 669 calving events [16]. A calving alert system for applications in extensive grazing was successfully trialed in regions with a cellular network consisting of a transceiver with GPS receiver embedded in the device sutured on the vulva of the cow, although the battery life was only one month [17]. However, beef cattle production in northern Australia resembles the conditions of wild or feral animals, which require more robust systems with geolocation of the birthing site. Furthermore, cellular coverage is very limited and animals roam in very large paddocks. Therefore, satellite communication for birth alerts may be one of the few options to make the data available in real-time to observe the newborn calves before they move away from the birthing site or are predated. Finally, calving alert devices would also require the ability to remain operational and implanted for long periods of time (e.g., up to six months) in extensive conditions with year-round calving and mustering only twice per year.

Limitations such as large-scale operations and the remote nature of production in extensive cattle herds means that the contribution of risk factors to calf mortality are not understood, requiring a method to track animals around birth to gather information to identify reasons for high calf mortality. Calving detection requires the following information: dam identification, time, and location when the calf is expelled, and these data should be transmitted in near real-time to allow for attending the birth site before the cow and offspring move away.

The hypothesis of the present study was that devices containing GNSS, two-way satellite communication, temperature sensors and accelerometers can be used to remotely detect changes at the time of calving and this information allows for the accurate detection of calving events and location in beef cattle extensively grazing. The objectives of the study were to (1) evaluate the effectiveness detecting calving events of GNSS collars with satellite communication and VIT birth alert devices, and (2) to study behavioral changes with calving measured by these devices in extensive commercial beef cattle.

\section{Materials and Methods}

All methods for this project have been approved by The University of Sydney Animal Ethics Committee (Animal Ethics Project Number 2017/1296).

The study was conducted on a large commercial beef enterprise in the western Victoria River Downs Region of the Northern Territory, Australia. The area has a tropical climate, with distinct wet and dry seasons. There is an average of $800 \mathrm{~mm}$ of rainfall per year, predominantly falling in the wet season between December and March. The average daily maximum temperature throughout the year was $35.0^{\circ} \mathrm{C}$ with a yearly average minimum of $21.2^{\circ} \mathrm{C}$ [18]. There were two trials run over two calving 
seasons, the first trial from April to September 2018 and the second trial from April to September 2019. Trial 1 was undertaken in a $33 \mathrm{~km}^{2}$ paddock, which contained three water points. Vegetation was primarily lightly wooded eucalypt, dominated by tropical tall grasses including Mitchell grass [19]. Trial 2 was $9 \mathrm{~km}$ east from the Trial 1 paddock on the same property, in a $7 \mathrm{~km}^{2}$ paddock with similar vegetation and terrain as Trial 1. Trial 2 paddock had one water point and was smaller to gain easier access to calving cows.

Trial 1. Animals were mustered in April 2018 with a helicopter (R-22, Robinson Helicopter Company, Torrance, CA, USA) as per routine mustering procedures in the region. Animals were brought into a set of holding yards to be processed for the biannual husbandry checks, pregnancy testing via rectal palpation and vaccinations. A total of 926 cows were pregnancy tested by a veterinarian. Trial cows were selected from this group based on the gestation stage. Cows due to calve before the 1st of September were eligible to be included in the trial, resulting in 157 pregnant cows and eight bulls. Trial cows were between 2 and 4 years of age, with $80 \%$ of the herd Brahman cows (Bos Indicus), with the remainder of the animals being composite or Shorthorn crosses. Bulls in the trial were a mix of Brahman (2), Composite (2) and Boran (4). All females were pregnancy tested, inspected for their health, provided with a management visual tag and electronic ear tag, weighed, and breed, body condition score and year of branding were recorded. Twenty $(n=20)$ cows were selected and fitted with GNSS collars containing GPS, temperature, relative humidity, UHF, VHF, two-way Iridium satellite communication and accelerometers. There were 10 GNSS collars with corresponding VIT devices for Brand 1 (Iridium Track M 3D collar, Lotek Wireless, Havelock North, NZ) and 10 GNSS collars with corresponding VIT devices for Brand 2 (Vertex Plus Iridium collar, Vectronic Aerospace $\mathrm{GmbH}$, Berlin, BB, Germany). The VITs were UHF ID coded and communicated with collars via UHF. Each of the collared cows had a VIT inserted by a veterinarian using an applicator, following the same insertion methods as the controlled internal drug release (CIDR) hormonal implant [20]. The cows were between 6 and 8.5 months of pregnancy according to rectal palpation. Animals were handled and subjected to standard commercial conditions for the duration of the trial. Animals were mustered back to the yards with a helicopter in October for calves to be weaned and for husbandry checks.

Trial 2. Trial animals were mustered in April 2019 following the same method and procedures as Trial 1. Ten $(n=10)$ cows at 5 months gestation were fitted with Brand 2 collars and corresponding Brand 2 VIT and allowed to graze in a smaller paddock $\left(7 \mathrm{~km}^{2}\right)$ where they were monitored closely over the calving period. Nine of the 10 cows with a VIT had not had an implant before. Cows were due to calve in August and were monitored at least 3 times a day during the calving period. Animals had access to one water point in the paddock.

During calving, cows were monitored once a day in Trial 1 and 3 times a day in Trial 2. Due to the size and terrain of the paddock in Trial 1, animals were tracked by first identifying their last known geolocation transmitted by the Iridium satellites and accessed using the proprietary software, and then beginning tracking on-site using the handheld Yagi VHF antenna and receiver to locate the cows in the paddock (Sirtrack Ultra, VSR041A, Sirtrack-Lotek, Havelock North, NZ). Animals were tracked on foot or via helicopter (R-22, Robinson Helicopter Company, Torrance, CA, USA). Tracking cows in the paddock was done by viewing the animal GNSS fixes retrieved from the manufacturers' webpage or software, and then using a handheld Yagi VHF antenna and receiver to locate the cows in the paddock.

Collars used GPS and Iridium satellite communication and recorded a fix every $30 \mathrm{~min}$. All fixes were stored on board the collar, with every 6th fix (approximately every $3 \mathrm{~h}$ ) being sent to the satellite. The frequency of satellite uploads could be selected by the user and changed at any time. These were available to view and download from proprietary software and corresponding company websites. Both collars summarized accelerometer data on board the collar every $5 \mathrm{~min}$ for each of the axes with values between 0 (no activity) and 255 (highest activity). In addition, Brand 2 collars recorded raw 2-axis accelerometer data at $4 \mathrm{~Hz}$. The $\mathrm{X}$-axis measures acceleration in forward and backward motions, Y-axis measures sideways and rotary motion, and Z-axis measures up and down movements using gravitational acceleration. Activity was measured four times per second simultaneously on each axis as 
the difference in acceleration between two consecutive measurements. Measurements were averaged over the user-selected sampling interval $(5 \mathrm{~min})$ and presented on a relative scale between 0-255, in units known as 'counts'. These data were then stored with the associated date, time and temperature.

Brand 2 VIT recorded temperature and accelerometer data every $5 \mathrm{~min}$, only retrievable by the manufacturer. However, these data were not recorded by the VIT of Brand 1. Once a VIT of Brand 1 was switched on, there was a 1-week delay before it was fully operational to allow the calculation of an average temperature for each animal as a 'benchmark' or 'normal' value. The Brand 1 VIT would not capture births if inserted into cows within 1-week of being switched on. Both VIT's had VHF transmitters to enable recovery in the field.

Brand 1 VIT had a wing opening of $57.17 \mathrm{~mm}$, a length of $88.91 \mathrm{~mm}$, a diameter of $16.34 \mathrm{~mm}$ and a weight of $26.3 \mathrm{~g}$. Brand 2 VIT had a wing opening of $70 \mathrm{~mm}$, a length of $70 \mathrm{~mm}$, diameter of $20 \mathrm{~mm}$ and weighed $30 \mathrm{~g}$ (Figure 1).

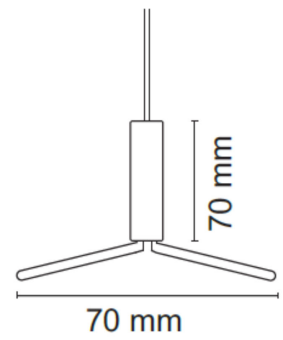

Figure 1. Sketch of the Brand 2 Vaginal Implant Transmitter (VIT) size dimensions.

Upon expulsion of the VIT, the drop in temperature, coupled with inactivity, activated the VIT proximity beacon. This signal was received by the cow's collar, triggering a birth alert that was transferred via the Iridium satellite system and sent as an email and GSM message to the user's mobile phone.

The thresholds and alert messages varied between the two birth alert systems (Table 1). The major difference was that the location coordinates were provided within Brand 1's birth alert message, but Brand 2 required access to the proprietary software to identify the location coordinates where the birth alert was activated.

Brand 1's system triggered the birth alert when there were both $60 \mathrm{~min}$ of inactivity and a temperature change of $\pm 3^{\circ} \mathrm{C}$ (Table 1 ). In addition, the Brand 1 birth alert was triggered if the VIT was inactive for $12 \mathrm{~h}$ regardless of vaginal temperature. Another major difference was that each Brand 1 collar could receive birth alert pulses from up to any 8 VIT beacons. This meant that once a VIT had been expelled (triggering birth alert pulses to be picked up by collars), any Brand 1 collar within UHF range (terrain dependent) could identify the birth alert and send a satellite notification of the birth. Therefore, birth alerts may be received multiple times for one VIT if several collars were nearby. This increased the likelihood of receiving a birth alert if there were other collared cows with Brand 1 nearby after birth. In contrast, the Brand 2 VIT could only communicate with its paired GNSS collar.

In comparison, Brand 2's inactivity threshold was $50 \mathrm{~min}$ and temperature threshold was below $34{ }^{\circ} \mathrm{C}$. Brand $2^{\prime}$ s system also had two types of alerts, each with different triggering criteria. The first alert type was an 'expelled alert' that was sent when the VIT was below $34^{\circ} \mathrm{C}$ for 50 min, changing the status of the VIT from 'implanted' to 'expelled'. However, once the 'expelled' alert was triggered, the status changed back to 'implanted' if the VIT detected movement for more than approximately $22 \mathrm{~min}$ and measured a temperature above $34{ }^{\circ} \mathrm{C}$ for the duration of this time. This process can occur multiple times for each collar and VIT combination, enabling multiple alerts to be received once the criterion was met. 
Table 1. Comparison of the two birth alert systems from vaginal implant tags (VIT) used in pregnant cows in the extensive beef cattle systems of northern Australia.

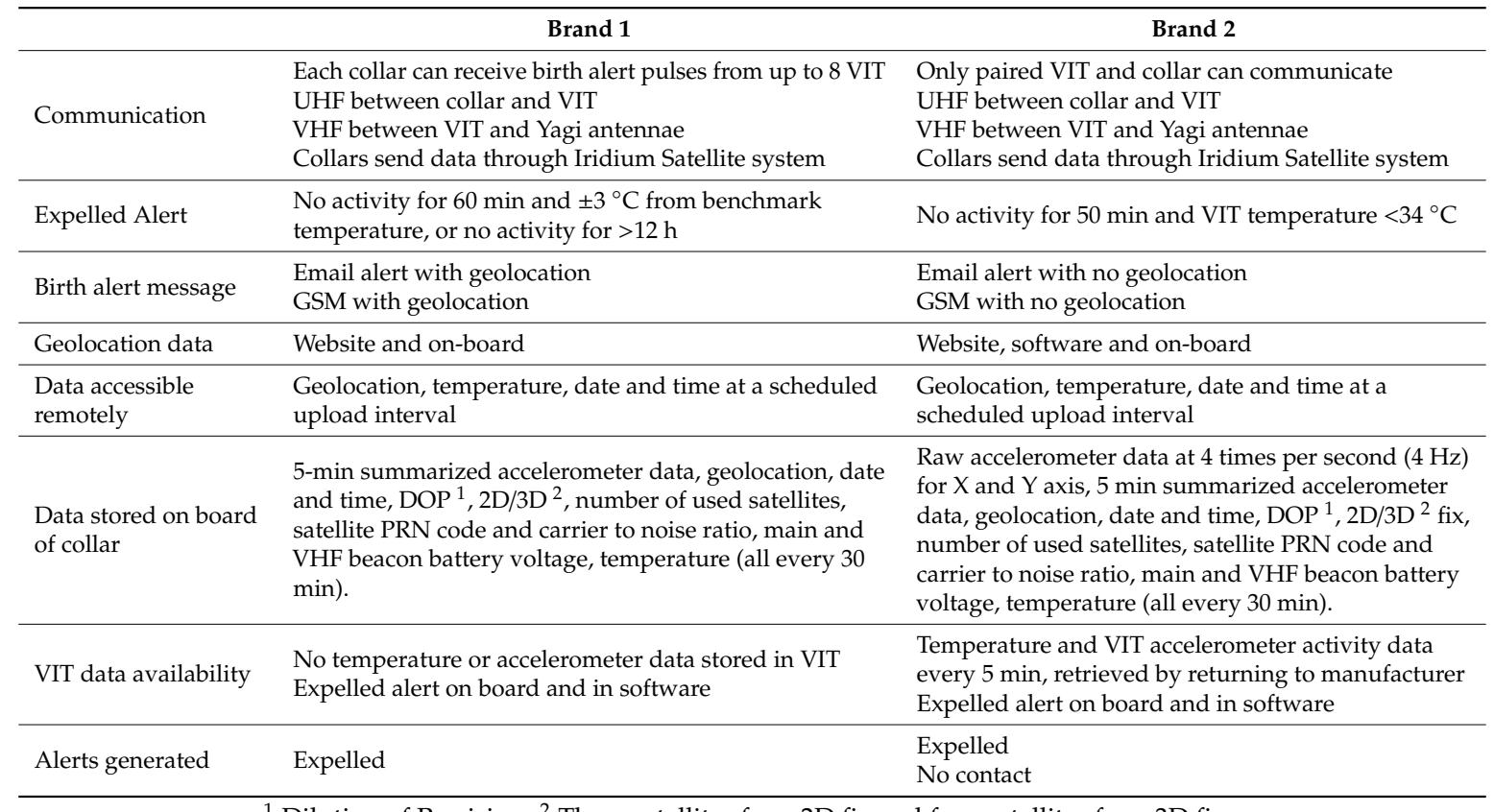

${ }^{1}$ Dilution of Precision. ${ }^{2}$ Three satellites for a 2D fix and four satellites for a 3D fix.

The second Brand 2 alert type was a 'no contact' alert. In normal circumstances the collar and the VIT communicate every $5 \mathrm{~min}$ in a 'listen interval', which confirms the VIT was still in place. If the collar and VIT are unable to communicate at their 'listen intervals' for one hour, the 'no contact' alert was triggered. This usually occurred when the cow had calved and the VIT was expelled, but the cow moved away from the VIT before an 'expelled' alert was triggered (i.e., the cow moved out of UHF range of the VIT before the 50-min threshold was reached, so an 'expelled' alert was never sent through to the collar). In this instance, a 'no contact' alert was repeated if the criteria were met. However, an 'expelled' alert may never be triggered unless the cow moves back within reach of the VIT again. For both Brand 2 and Brand 1, the birth alert was missed if the cow moved away from the birth site and out of the UHF range of the VIT within 50/60 min of birth. In Brand 2 collars, this would result in a 'no contact' alert.

The success of both birth alert systems in providing a timely notification of birth relied on two main factors; (1) that the collar and VIT were able to communicate via UHF to create a birth alert, and (2) that the collar had a clear path of communication to the satellite enabling an alert to be sent. If the collar was hindered by vegetation, or the position of the collar on the cow's neck was not facing upwards, the birth alert notification would be delayed.

\section{Statistical Analysis}

The gestation stage when the VIT was implanted was determined by an experienced veterinarian upon rectal palpation and a gestation of 282 days was assumed to determine the calving date. The number of days that the VIT remained implanted was calculated as the date of confirmed VIT expulsion minus the date of implantation. The date of the VIT expulsion was confirmed from the data retrieved from the VIT, as well as daily visual and VHF tracking of each cows' VIT over the calving period. The number of days that the VIT was expected to remain implanted was calculated as expected calving date minus VIT implant date. In addition, the number of days between observed and expected calving date were calculated for those animals with calf sighting confirmed upon birth. Descriptive statistics for vaginal temperature was calculated, while the VIT remained implanted in the cow and included external temperature and the VIT was expelled to understand the potential impact 
of ambient conditions on missed or false alerts. The time lapse to receive a birth alert was calculated by the difference between the date and time and the expelled alert was recorded on the collar and the time the email and GSM were received. This was calculated for all animals that had both a true or false alert. The distance travelled by cows between the time when the expelled alert was registered by the collar and the time the email notification was received was calculated as the distance between both geolocations. The distance travelled by cows during the $1 \mathrm{~h}$ period after the expelled alert was registered was also calculated. The performance of the VIT was assessed using a confusion matrix: true alert or true birth (true positive; TP), false alert (false positive; FP), missed birth (false negative; FN), and true no alert (true negative; TN). A true positive was defined as a birth alert received and the newborn calf confirmed by sighting within the first $24 \mathrm{~h}$ after receiving the alert. A true negative was when a birth alert was not received, and no calf was sighted on the paddock. A false positive was defined as a birth alert received but no calf being sighted and the cow showing clear evidence of still being pregnant [21,22].

A false negative was defined as no birth alert received but a newborn calf being sighted in the paddock.

The accuracy, sensitivity, specificity and precision of the birth alert systems was assessed using a binary classification with the following equations [23].

$$
\begin{gathered}
\text { Accuracy }=(\mathrm{TP}+\mathrm{TN}) /(\mathrm{TP}+\mathrm{TN}+\mathrm{FP}+\mathrm{FN}) \\
\text { Sensitivity }=\mathrm{TP} /(\mathrm{TP}+\mathrm{FN}) \\
\text { Specificity }=\mathrm{TN} /(\mathrm{TN}+\mathrm{FP}) \\
\text { Precision }=\mathrm{TP} /(\mathrm{TP}+\mathrm{FP})
\end{gathered}
$$

All data from the GNSS collars and VIT were trimmed for the analysis 30 days either side of calving. Linear mixed-effects regression models were used to analyze the GNSS and activity data in relation to the day of calving using the 'lme4' package in $\mathrm{R}$, version 3.6 .3 [24], with the day from calving as the dependent variable and the cow ID and date included as random effects. Differences between means were calculated for the day of calving and day after calving against all other 59 days around calving using the Bonferroni adjustment. Temperatures of the VIT were removed from the analysis below $37.13^{\circ} \mathrm{C}$ and above $40.76{ }^{\circ} \mathrm{C}$ in Trial 1 , and $37.60{ }^{\circ} \mathrm{C}$ and $40.91{ }^{\circ} \mathrm{C}$ in Trial 2 in agreement with previous studies [25-28]. Temperature outside these ranges were confirmed to be during periods when the VIT was outside the cow through visual checking of VIT in the paddock and VHF signal of VIT inside each cow. The 'Move' package [29] was used to calculate the distance travelled between each $30 \mathrm{~min}$ fix of the GNSS data. Daily distance travelled was calculated as the sum of each 30 min distance per day, daily average activity of the X-and Y-axis counts measured by the accelerometer, and the daily average VIT temperature for each cow was calculated. Only data from cows with confirmed date of births, as described above, were used for the analysis of distance travelled and activity relative to day of calving. Distance travelled was log transformed in both trials before analysis to normalize the data and to obtain P values; however, the mean values were presented in their original units. Only days significantly different from the day of calving and day 1 after calving were presented for distance and activity graphs, to account for animals calving at different times on the day of calving. The two birth alert systems were also compared using logistic regression with the brand as the only fixed effect and alert received or not as the dependent variable using the 'glm' stats package ( $R$ version 3.6.3) [24].

\section{Results}

Cows in Trial 1 were implanted with the VIT at approximately two months before calving and cows in Trial 2 were implanted at four months before calving (Table 2). However, the VIT remained implanted in the cows for approximately one to three months on average for Trial 1 and 2, respectively. Calving occurred between 10 days before and 71 days after the expected calving date recorded by 
the veterinarian in Trial 1; however, it ranged from -1 to 33 days in Trial 2 (Table 2). The time lapse between the expelled alert recorded on the collar and the time when the email and GSM alerts were received was similar between trials, ranging from $-87 \mathrm{~min}$ (email/GSM was received before the time of VIT expulsion was recorded) to $1285 \mathrm{~min}$ (Table 3). Six of the 8 true birth alerts were sent via email within 56 min of expulsion and two alerts had a time lapse of 12 and $18 \mathrm{~h}$, with the cow travelling a distance of $750 \mathrm{~m}$ and $680 \mathrm{~m}$, respectively, in the time between the expulsion and email being received (Table 2).

Table 2. Descriptive statistics for Trial 1 and 2 showing the number of observations, minimum mean and maximum values and the standard deviation for key measurements recorded in each trial.

\begin{tabular}{|c|c|c|c|c|c|}
\hline & $n$ * & Min & Mean & Max & SD \\
\hline \multicolumn{6}{|l|}{ Trial 1} \\
\hline Live weight, kg/hd & 20 & 245 & 372.10 & 497 & 57.91 \\
\hline Days pregnant when VIT implanted & 20 & 182.50 & 215.96 & 258.54 & 18.86 \\
\hline Days VIT remained implanted & 17 & 3.42 & 31.13 & 71.39 & 18.50 \\
\hline Days VIT implant to expected calving date & 19 & 13 & 57.47 & 91 & 19.30 \\
\hline Days between expected and observed calving date & 16 & -10 & 29 & 71 & 22.81 \\
\hline Time lapse- expelled to email (min) & 20 & -87 & 312.75 & 1285 & 430.05 \\
\hline Distance travelled- expelled to email (m) & 8 & 0 & 178.75 & 750 & 310.10 \\
\hline Distance travelled- expelled to $1 \mathrm{~h}$ after $(\mathrm{m})$ & 8 & 0.59 & 158.92 & 643.60 & 268.17 \\
\hline Number of expelled alerts per animal & 19 & 0 & 2.89 & 11 & 3.31 \\
\hline Number of No-contact alerts per animal & 9 & 2 & 12.11 & 43 & 11.37 \\
\hline Time between alert and calf sighting (days) & 14 & -4 & 13 & 47 & 16.08 \\
\hline Vaginal temperature (internal) $\left({ }^{\circ} \mathrm{C}\right)$ & 17,192 & 37.13 & 38.82 & 40.76 & 0.48 \\
\hline VIT temperature (all recorded) $\left({ }^{\circ} \mathrm{C}\right)$ & 17,630 & 8.16 & 38.51 & 60.52 & 2.76 \\
\hline Ambient temperature on date of VIT expulsion $\left({ }^{\circ} \mathrm{C}\right)$ & 12 & 12.80 & 22.77 & 33.90 & 5.82 \\
\hline Ambient temperature over $60 \mathrm{~d}$ calving period $\left({ }^{\circ} \mathrm{C}\right)$ & 60 & 7.50 & 22.00 & 35.60 & 6.33 \\
\hline Distance travelled non-calving days $(\mathrm{km} / \mathrm{d})$ & 397 & 0.43 & 6.45 & 17.11 & 2.79 \\
\hline Distance travelled on calving date $(\mathrm{km} / \mathrm{d})$ & 8 & 0.93 & 5.54 & 12.98 & 4.11 \\
\hline Activity X-axis calving period (counts) & 397 & 11.04 & 43.01 & 71.89 & 9.24 \\
\hline Activity X-axis- day of calving (counts) & 8 & 25.89 & 35.95 & 46.89 & 5.88 \\
\hline Activity Y-axis calving period (counts) & 397 & 8.59 & 38.38 & 87.13 & 12.14 \\
\hline Activity Y-axis- day of calving (counts) & 8 & 15.28 & 33.61 & 58.06 & 13.57 \\
\hline \multicolumn{6}{|l|}{ Trial 2} \\
\hline Live weight, kg/hd & 10 & 402 & 455.90 & 494 & 30.80 \\
\hline Days pregnant when VIT implanted & 10 & 152.08 & 152.08 & 152.08 & 0.00 \\
\hline Days VIT remained implanted & 10 & 24 & 98.66 & 134.93 & 40.56 \\
\hline Days VIT implant to expected calving date & 10 & 122 & 122 & 122 & 0.00 \\
\hline Time lapse- expelled to email (min) & 5 & -8 & 235 & 601 & 3.19 \\
\hline Days between expected and observed calving date & 10 & -1 & 12 & 33 & 9.00 \\
\hline Number of expelled alerts per animal & 10 & 0 & 0.90 & 3 & 1.14 \\
\hline Number of No-contact alerts per animal & 10 & 1 & 14.40 & 58 & 15.46 \\
\hline Vaginal temperature (internal) $\left({ }^{\circ} \mathrm{C}\right)$ & 105,233 & 37.60 & 38.49 & 40.91 & 0.30 \\
\hline VIT temperature (all recorded) $\left({ }^{\circ} \mathrm{C}\right)$ & 161,632 & 4.30 & 35.35 & 62.67 & 6.72 \\
\hline Ambient temperature on date VIT expulsion $* *\left({ }^{\circ} \mathrm{C}\right)$ & 8 & 15.30 & 21.98 & 27.10 & 3.94 \\
\hline Ambient temperature over $60 \mathrm{~d}$ calving period $\left({ }^{\circ} \mathrm{C}\right)$ & 60 & 14.10 & 27.43 & 37.00 & 4.87 \\
\hline Distance travelled non-calving days $(\mathbf{k m} / \mathrm{d})$ & 404 & 1.35 & 6.12 & 15.51 & 2.30 \\
\hline Distance travelled on calving date $(\mathrm{km} / \mathrm{d})$ & 7 & 1.35 & 5.00 & 8.52 & 2.80 \\
\hline Activity $X$-axis calving period (counts) & 404 & 18.07 & 30.97 & 50.26 & 6.35 \\
\hline Activity X-axis- day of calving (counts) & 7 & 19.82 & 31.00 & 42.25 & 7.36 \\
\hline Activity Y-axis calving period (counts) & 404 & 13.24 & 28.69 & 66.62 & 7.20 \\
\hline Activity Y-axis- day of calving (counts) & 7 & 13.24 & 30.20 & 42.35 & 9.84 \\
\hline
\end{tabular}

${ }^{*} n$ calculated from number of cows with confirmed information for each variable. ** Actual date and time of birth is different as no true birth alerts were received in trial 2.

The number of expelled alerts received per VIT was three-fold higher in Trial 1 compared to Trial 2, but the number of no-contact alerts was similar (Table 2). Vaginal temperature ranged between $\pm 3.63{ }^{\circ} \mathrm{C}$, while implanted in Trial 1 and by $\pm 3.31^{\circ} \mathrm{C}$ in Trial 2 . However, only 13 VIT devices were recovered from the trials to retrieve temperature data (Table 3 ). The average distance travelled on the day of calving was approximately $1 \mathrm{~km}$ shorter compared to the average of other days for both Trials (Table 2). 
Table 3. Comparison of the performance of two brands of birth alert systems based on vaginal implant tags fitted to pregnant beef cows in extensive production systems (Trial 1 and 2).

\begin{tabular}{lcccc}
\hline & \multicolumn{2}{c}{ Trial 1 } & \multicolumn{2}{c}{ Trial 2 } \\
\cline { 2 - 5 } & Brand 1 & Brand 2 & $p$-Value & Brand 2 \\
\hline True birth alert (\%) & $0.30 \pm 0.15$ & $0.56 \pm 0.17$ & 0.26 & 0.00 \\
False birth alert (\%) & $0.30 \pm 0.15$ & $0.44 \pm 0.17$ & 0.51 & 0.50 \\
Missed birth alert (\%) & $0.40 \pm 0.16$ & $0.00 \pm 0.00$ & 0.01 & 0.50 \\
True birth event (\%) & $1.00 \pm 0.00$ & $0.78 \pm 0.14$ & 0.07 & 1.00 \\
Alert time lapse ${ }^{1}$ (mins) & $341 \pm 173$ & $290 \pm 153$ & 0.829 & $235 \pm 285.63$ \\
VIT retrieved & 2 & 5 & NA & 8 \\
Accuracy (\%) & 50 & 55 & NA & 0 \\
Specificity (\%) & 60 & 25 & NA & 0 \\
Sensitivity (\%) & 40 & 83 & NA & 0 \\
Precision (\%) & 50 & 62.5 & NA & 0 \\
\hline
\end{tabular}

${ }^{1}$ The time between VIT expulsion was recorded by the system, versus the time the research team received the VIT expulsion email for both true and false birth alerts.

Of the 20 collared animals in Trial 1, eight were true birth alerts (calf confirmed after receiving alert), eight were missed births (calf was seen but no alert received) and three were false alerts (alert received but no calf seen). Cows were classed as still pregnant after receiving a false alert by their physical appearance [21,22], and also after sighting their newborn calf at least seven days after the false alert was received. There was one Brand 2 collar that was broken and removed from analysis.

Both brands performed similarly for true $(p=0.258)$ and false $(p=0.51)$ birth alerts, but Brand 2 showed lower missed birth alerts compared to Brand 1 ( $p=0.013$; Table 3). However, $75 \%$ (three out of four) of Brand 1's missed alerts occurred due to calving happening within the one-week calibration period after implant. The Brand 2 birth alert system had slightly better accuracy and over two-fold better sensitivity, but lower specificity compared to the Brand 1 system (Table 3). Only 37\% of all VIT were retrieved from the paddock during Trial 1 . No calving difficulties such as dystocia were observed over the trial periods. In Trial 1, seven of the 19 calves (36\%) went missing and their dams returned to the yards without a calf at weaning time. None of these calves had confirmed death sightings. In trial 2, 2 of the 10 calves (20\%) were confirmed dead and necropsy samples taken. Necropsy samples showed that one calf's death was caused by septicemia and the other was a suspected dog attack.

In Trial 2, there were no true birth alerts, five false alerts and five missed alerts (Table 3 ). In addition, two VIT were expelled early ( 24 and 28 days after insertion), and therefore, reinserted 61 and 70 days before true calving time. Subsequently, one was expelled prematurely again, 10 days prior to true calving. The VIT were expelled on average $35.82 \pm 40.65$ days before calving. Three calves were found with their respective mothers before the birth alert was received from the software (false negatives). Eight out of 10 VITs were retrieved.

The mean distance travelled by collared cows during the calving period, defined as 30 days each side of the calving date, was similar between trials (Table 2). The day from calving affected distance travelled by cows in both trials $(p<0.05)$ with animals travelling further on days $-3,-9,-20,15$, and 26 compared to calving day and day 1 in Trial 1 ( $p<0.05$; Figure 2a), and travelling further on day -2 compared to the calving day in Trial $2(p<0.05$; Figure 2$)$. The average daily activity on the $\mathrm{X}$-axis of the accelerometers was affected by the day from calving in both trials $(p>0.05$; Figure 3$)$. However, the average activity of the Y-axis was affected by the day from calving in Trial $2(p<0.05)$, but not in Trial $1(p=0.24$; Figure 3$)$. The average distance travelled within the first hour after a true birth alert in Trial 1 was $158 \mathrm{~m}$, with only two animals having a distance greater than $7 \mathrm{~m}$ in the hour after the expelled alert was registered by the collar (Table 2). Of the eight true birth alerts in Trial 1, the distance cows travelled between the registration of the alert on the collar and the notification email was $0 \mathrm{~m}$ in six out of eight cases. In the other two alerts, the cows travelled $680 \mathrm{~m}$ and $750 \mathrm{~m}$, respectively. This distance could not be calculated for Trial 2 as there were no true birth alerts. The Pearson correlation coefficient 
between the daily average $X$ - and Y-axis counts in Trial 1 was $0.66(p<0.001)$ and 0.80 in Trial 2 (data not shown; $p<0.001)$. The Pearson correlation coefficient between distance travelled and the average $X$ - and Y-axis in Trial 1 was 0.51 and $0.58(p<0.001)$, and 0.51 and 0.77 in Trial $2(p<0.001)$, respectively.

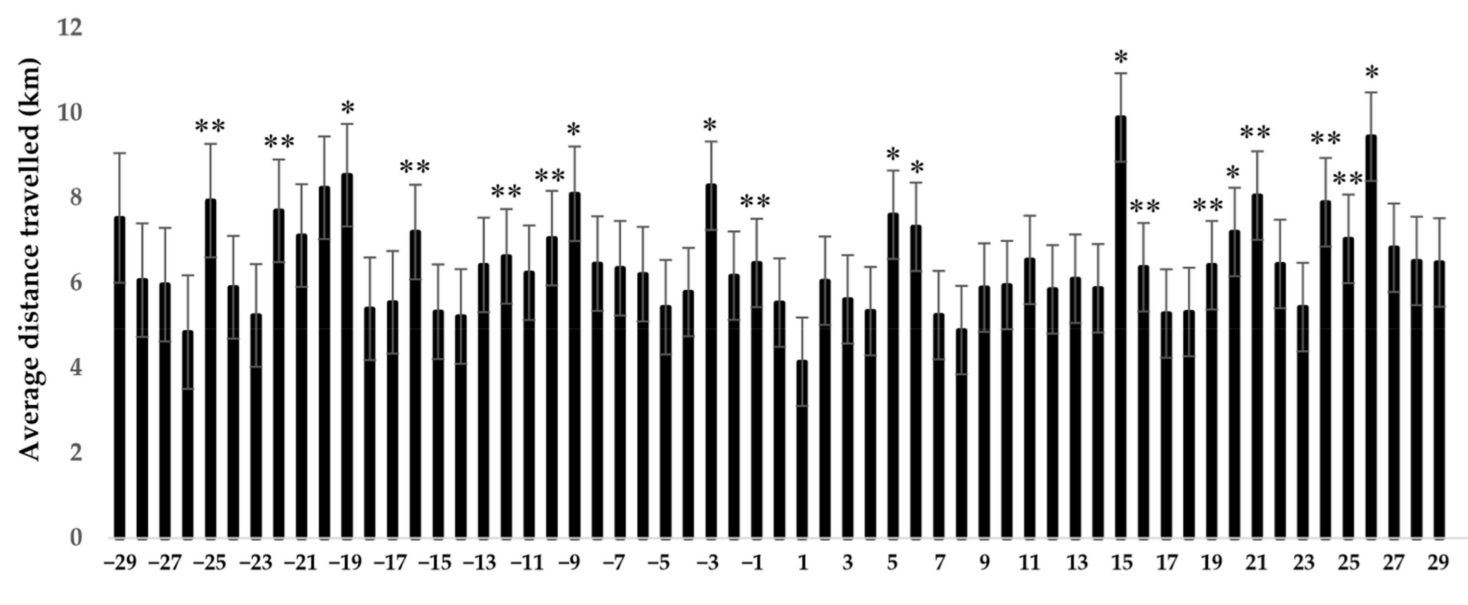

Day to calving

(a)

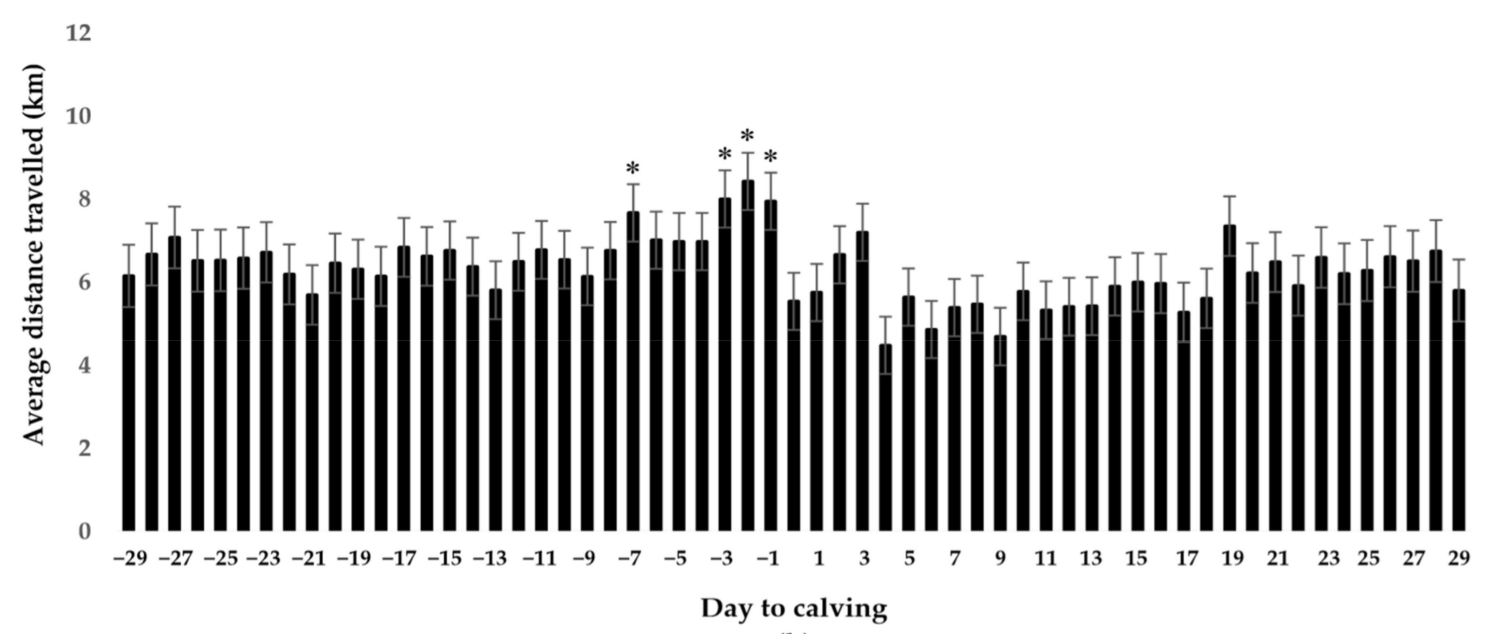

(b)

Figure 2. Average distance travelled per day by collared cows 30 days each side of the calving date in Trial $1(\mathbf{a})$ and $2(\mathbf{b})$. Means with an Asterix $\left({ }^{*}\right)$ indicate a significant difference from the day of calving $(p<0.05)$. Means with two Asterix $(* *)$ indicate a significant difference from day $1(p<0.05)$. Only collared cows with a confirmed calving date ( $n=8$ in Trial 1 and $n=7$ in Trial 2) were included.

Approximately 17,000 vaginal temperature datapoints were collected from five Brand 2 cows in Trial 1 and approx. 160,000 vaginal temperature datapoints from eight Brand 2 cows in Trial 2. Vaginal temperature data for three Brand 2 VIT devices retrieved in Trial 1 are shown in Figure 4 with cow 1 and 2 calving after sunset and the VIT experiencing a sharp reduction in temperature, which triggered the birth alert. However, cow 3 expelled the VIT at noontime, showing a sharp decrease followed by a sharp increase in temperature and the birth alert was not triggered.

There were clear temperature patterns within and between days in all animals, with a large variability of over $3{ }^{\circ} \mathrm{C}$ during the day. Diurnal patterns were evident with temperature increasing during the morning and decreasing during the night to reach the lowest values at the end of the night (Figure 5). 

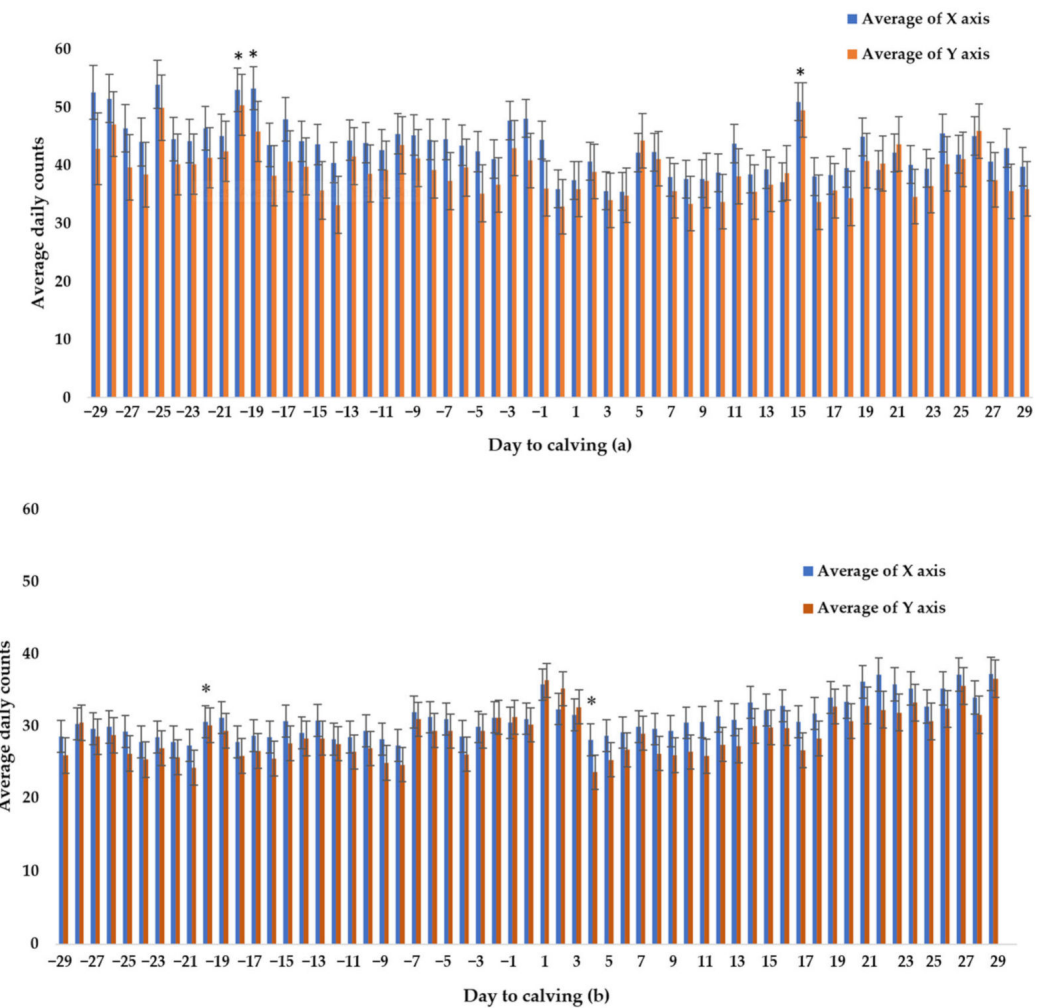

Figure 3. Average activity counts of the accelerometer X- and Y-axis for collared cows 30 days each side of the calving date for Trial $1(\mathbf{a})$ and Trial $2(\mathbf{b})$. Means with an Asterix $\left(^{*}\right)$ indicate a significant difference from the day of calving $(p<0.05)$. Means with two Asterix $(* *)$ indicate a significant difference from day $1(p<0.05)$. Only collared cows with a confirmed calving date $(n=8$ in Trial 1 and $n=7$ in Trial 2) were included.

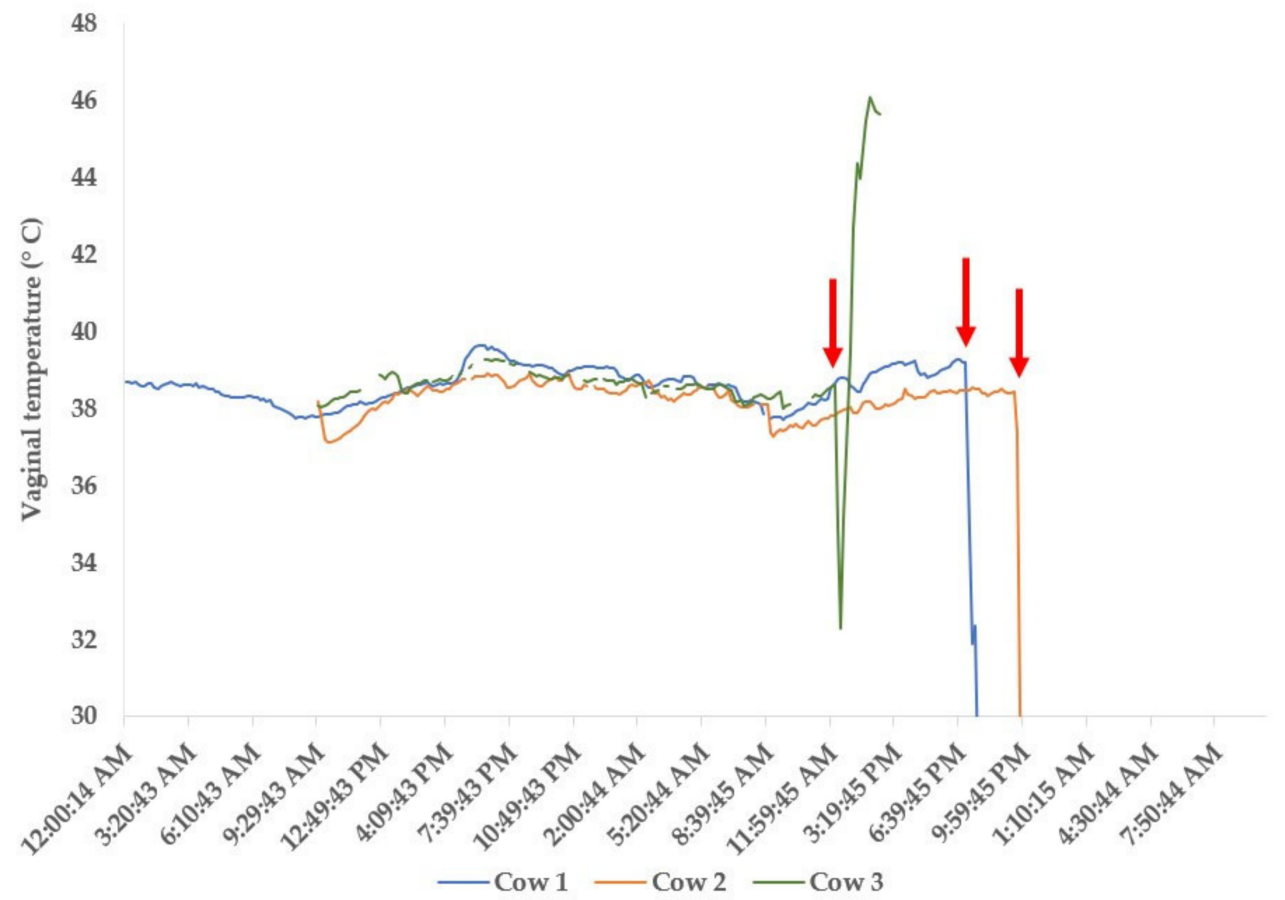

Figure 4. Vaginal implant tag temperature of three cows in the lead up to calving. Arrows indicate the VIT expulsion time. 


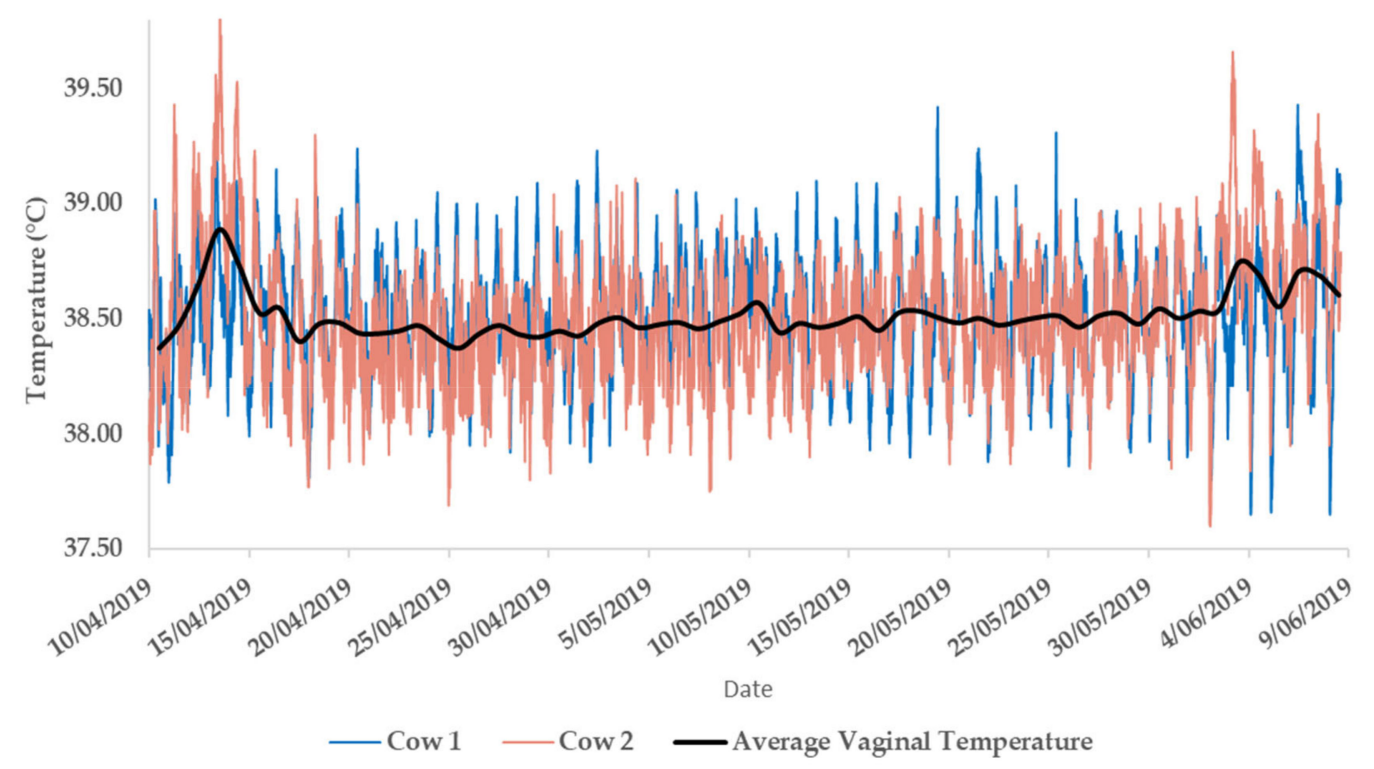

Figure 5. Vaginal temperature recorded at 5-min intervals from two cows in Trial 2, showing the diurnal pattern within days (pink and blue lines), and the daily average vaginal temperature (black line) to show variability across days for the 2-month period. Temperature data taken from April to June 2019.

Average activity data from VIT in Trial 2 show the activity patterns for eight cows over the trial period (Figure 6). The activity level dropped to zero after the early expulsion of the VIT for two cows, while the other VIT ran out of battery before expulsion occurred, so drops in activity were not captured (Figure 6).

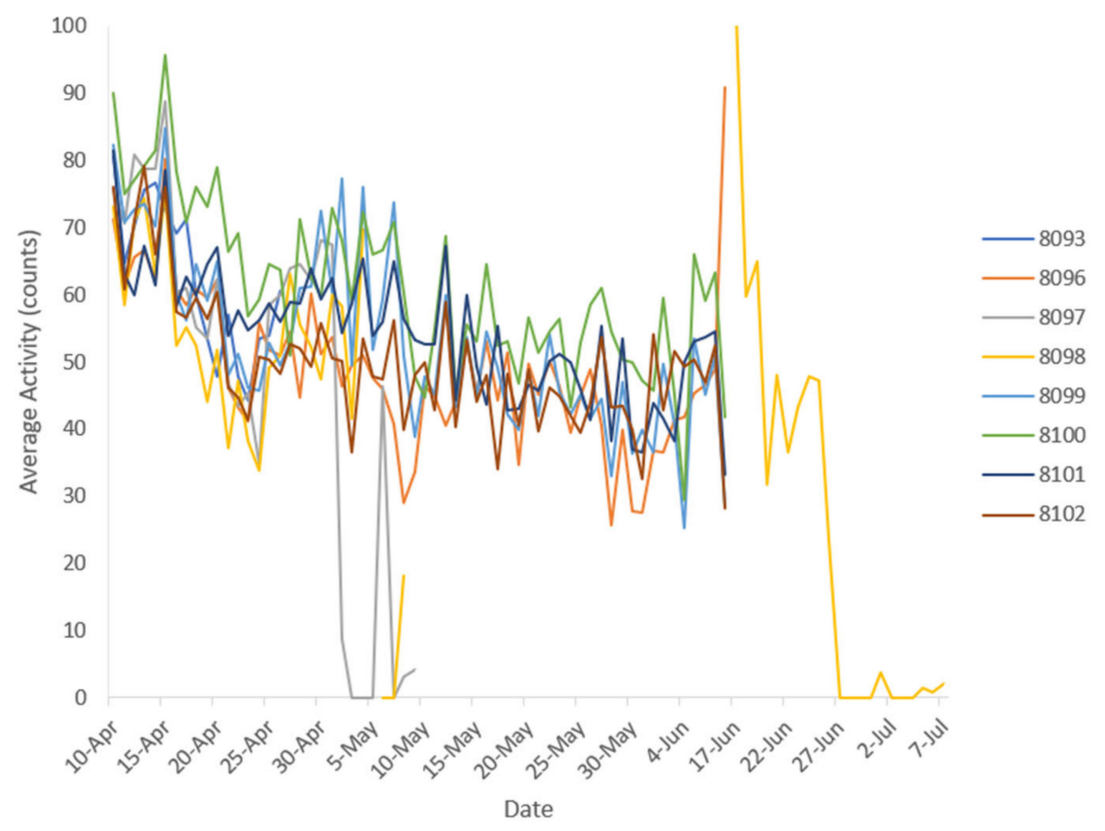

Figure 6. Average activity data from Vectronic vaginal implant tags (VIT) in Trial 2. All VIT retrieved in Trial 2 are shown.

There was a higher density of geolocation fixes near the water and supplementation points (data not shown), however most cows calved in less frequented areas of the paddock. The tracks for three collared cows in Trial 1 are shown as an example to highlight the spatial scale of the paddock and the 
difficulty in tracking calves in Trial 1 (Figure 7). Cows 4, 5 and 8 walked 5.32, 2.31 and $3.54 \mathrm{~km} /$ day, respectively, on the day of calving while their average distance walked over the calving period was $6.94,6.19$ and $6.16 \mathrm{~km} /$ day, respectively.

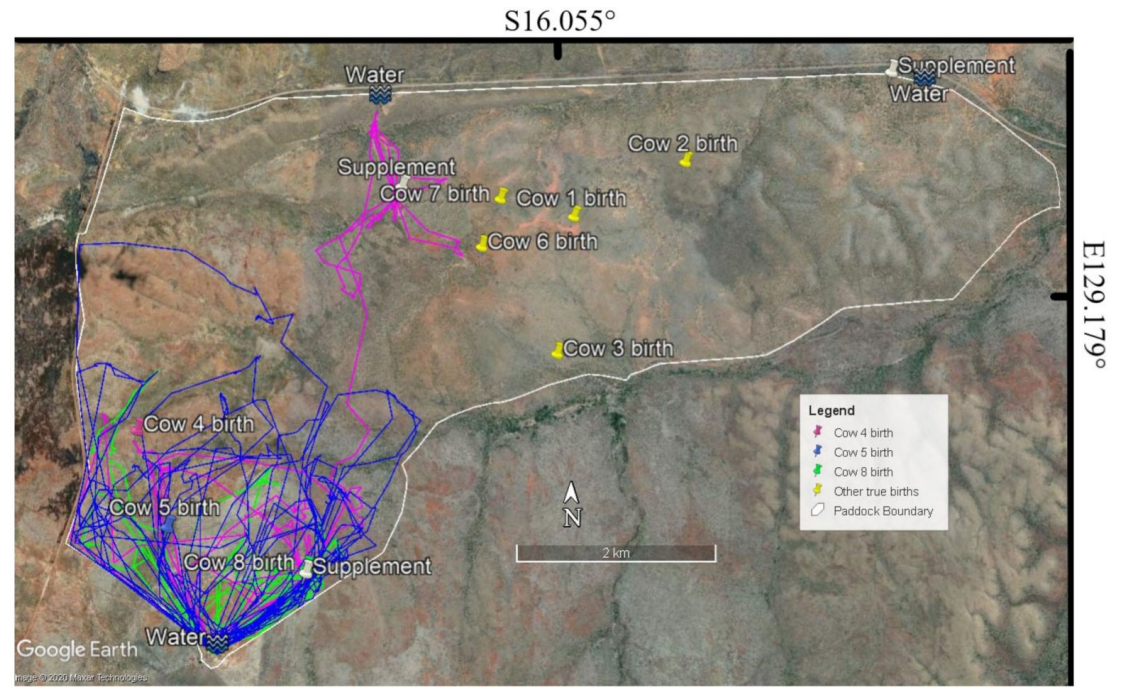

Figure 7. Satellite image showing the tracks and fixes of three cows from Trial 1, one week each side of calving. White outline shows the boundary of the paddock. The eight true birth alerts are shown with their respective collars, as well as supplement and water points within the $33 \mathrm{~km}^{2}$ paddock.

\section{Discussion}

This study evaluated the suitability of GNSS collars with Iridium satellite communication and paired VIT to detect calving time and location in the extensive beef production systems of northern Australia where no cellular network is available. To the best of our knowledge, this is the first study to use this technology to detect calving events in cattle and to compare two brands of commercially available birth alert systems. The study also provided new information about the movement patterns of animals around calving time in a large-scale cattle breeding operation. This information could help to improve animal production and welfare in extensive beef cattle industries. In this study, important features for detecting birth alerts included: the time and location of a birth or VIT expulsion within the shortest possible timeframe. The thresholds for triggering a birth alert were 50 and 60 min (Brand 1 and 2) of no activity; therefore, it was expected that a birth alert notification would be available as soon as possible after this time lapse using satellite communication. A key feature of birth alerts would be their ability to capture all true birth events, so that no missed or false alerts were received. Remote areas with difficult terrain, dense vegetation, and lack of infrastructure (e.g., electricity, office, internet) reduced accessibility, and therefore the ability to locate and observe cattle to understand losses. Using birth alert systems could provide vital information during the calving period to gain knowledge about calf mortality. However, only $27.6 \%$ of births were accurately identified, $41.4 \%$ were false alerts and $31.0 \%$ of births were missed on average for both brands. Therefore, these systems were unsuitable and inaccurate to reliably detect calving or find newborn calves in this environment. These poor results agree with previous findings using similar technology in elk, deer, and bighorn sheep $[4,14,15,30,31]$.

Possible reasons for low accuracy of birth alert devices could include the following: (1) devices were not designed for long term deployment, (2) delays with connection and data transmission using satellite technology, (3) inappropriate thresholds for triggering alerts under these environmental conditions, (4) limitations of accessibility to the calving sites, and (5) other environmental conditions that may have affected cattle behavior around calving, such as the presence of wild dogs [32].

The length of time the VIT was inserted and that subsequently remained implanted was dependent on stage of pregnancy at the time of VIT insertion, which could not be predicted prior to mustering of 
the animals. Previous research demonstrated that the retention of VIT declined with time $[10,12,13]$ and was evident in this study with a 70\% early expulsion rate in Trial 2, where most VIT were expelled after approximately 3 months. Intrauterine devices are commonly used in cattle to deliver hormones to bring cattle into estrus using slow release devices [20]. These devices have similar design to the VIT used in this study and are generally implanted for 7 to 12 days [33]. The developers of the CIDR device stated that their product may not be suitable for intravaginal insertion for periods longer than four weeks [34], much less than the time frames used in this study. In a study with Japanese Black cows [16], VIT were only implanted seven days prior to calving, making the chance of early expulsion much lower than the present study. The availability of WIFI and having cattle in a housing environment also made communication with the sensor more reliable and timely compared to the present study. Therefore, these results suggest that deployments over three months are not feasible at present and VIT should be inserted between one and three months prior to calving to improve reliability. The VIT retention issues in deer were also evident in the work by Tatman et al. [35], who suggested that the wing length of the VIT and the geographic location of the animals may have an impact on retention rates. The effects of long term intravaginal device placement has not been widely studied in cattle, however a study by Zartman et al. [36] showed no physical or physiological impacts after 107 days implantation of vaginal temperature transmitters in 18 Holstein heifers. The design of the temperature transmitters used by Zartman et al. were composed of multiple anchoring 'fingers' stabilizing the transmitter inside the vagina. The design (fingers or wings) and length of the VIT implantation may result in vaginal contractions, which may have caused early VIT expulsion. However, in a study that focused on the welfare of elk fitted with VIT [15], there was no evidence that the VIT had a negative impact on reproductive performance. Furthermore, there were no signs of birthing complications in animals fitted with VIT, which was also the case in this trial. In Trial 2, the VIT devices were meant to be implanted for four months, but on average these were expelled at approximately three months. Unlike other studies using vaginal temperature sensors for cattle to detect calving [16], this study required an extended period of implantation before birth, which may have impacted its effectiveness. In addition to the early expulsion seen in Trial 2, the VIT used up their on-board data storage capacity within three months after insertion, and therefore, temperature and activity data were not recorded after this period. However, the VIT and collar were still able to communicate, and birth alerts were possible. Therefore, the design, size, and battery life of VIT to operate and be retained for extended periods of time in cattle need further research and improvement for applications.

The main limitation of the birth alert systems was the high number of missed and false alerts, which could have been caused by a range of environmental and technological factors. Missed alerts could occur due to failed UHF communication between the collar and the VIT. For example, the alert may be missed if a cow moved out of UHF range of the expelled VIT before the alert was triggered at 50 or 60 min depending on the brand. The fact that cows travelled up to $13 \mathrm{~km}$ on the day of calving and up to $643 \mathrm{~m}$ during the first hour after the expelled alert in Trial 1 confirms this could have been a major contributing factor to missed birth alerts. A missed alert could also occur if the VIT did not meet the required temperature and activity thresholds. With Brand 1 VIT, a change in temperature less than $\pm 3{ }^{\circ} \mathrm{C}$ from the benchmark established for the first week after insertion did not trigger a birth alert and it assumed that the VIT was still inside the cow. The missed alerts for Brand 1 must be interpreted with caution because three of the four missed alerts were due to a calving event occurring inside this one-week calibration period. However, no animals in the trial were fetal aged more than 8.5 months pregnant at the time of VIT insertion, and thus, Brand 1 missed alerts were due to the cows calving earlier than expected rather than a fault in the VIT.

The reliance on temperature changes in the VIT to trigger alerts could be a limitation of this technology [23] where the ambient temperature may be close to the animal's body temperature, such as in tropical or subtropical conditions. If animals were placed in housing conditions where the temperature was lower and there were shaded areas, the likelihood of the birth alert success would likely be higher [16,31]. If the VIT of Brand 2 was expelled during the middle of the day, the outside 
temperature may have been above the $34^{\circ} \mathrm{C}$ threshold and solar radiation could also have contributed to maintaining high temperature of the VIT, as seen in the reported data with values above $60{ }^{\circ} \mathrm{C}$ which would not allow the alert to be triggered. The vaginal temperature was on average $38.66{ }^{\circ} \mathrm{C}$, with the lowest recorded at $37.13^{\circ} \mathrm{C}$ compared to the maximum ambient daily temperatures during the calving season months of $35.6{ }^{\circ} \mathrm{C}$ in Trial 1 and $37.0^{\circ} \mathrm{C}$ in Trial 2 [18]. Therefore, the temperature of the expelled VIT may not reach the threshold required fast enough to trigger an alert for either brand resulting in a missed alert. Ambient temperature was shown to have an impact on VIT, emitting an expulsion pulse in a study using VIT in deer [31]. It showed that the probability of VIT emitting an expulsion alert declined as ambient temperature rose, with almost zero probability of an expulsion alert if temperatures were above $35^{\circ} \mathrm{C}$, however this fluctuated slightly, depending on vegetation type and shade or sun exposure [31].

A false alert could be triggered when a cow remained inactive for over an hour and reached the required temperature threshold, despite not expelling the VIT. However, the VIT temperature data demonstrated that this had not occurred in this trial.

The time between VIT expulsion and receiving the birth alert notification varied greatly with up to 12 and 18-h delay. In these cases, cows travelled around $700 \mathrm{~m}$ between the expelled alert time and email notification, showing the challenges in reaching cows and calves in an extensive system after receiving a birth alert. This time lapse could be due to poor connection between the collar and the satellites, caused by tree cover, rocky or hilly terrain, thereby causing a delay. The greater the time lapse between calving or VIT expulsion and attendance to the birth site, the less likely it was to find the calf for data recording. Furthermore, the time of the VIT expulsion in relation to the time of calf expulsion is unknown and further research is required to determine this. Overcoming limitations of the time required for the satellite communications would require a change to communication protocols such as the use of LoRaWAN (Long Range) [37] or low-power wide-area network (LPWAN) [38].

The distance travelled by cows decreased during the first few days after calving in Trial 2, but not in Trial 1, which could have been a result of animals in Trial 2 being in a smaller paddock $\left(7 \mathrm{~km}^{2}\right)$ compared to animals in Trial $1\left(33 \mathrm{~km}^{2}\right)$. This is the first study assessing cow movements around calving time in extensive commercial systems. The high activity of cows on the day of and after calving observed could be due to increased alertness of cows and need to continuously move to avoid calf predation by wild dogs [39], which were regularly seen during the calving season, and also the need to attend the water point to drink, abandoning the calving site. These findings highlight the limitations of VIT to satellite communication technology in detecting birthing events for animal species that move large distances after birth. With cows remaining mobile after birth, this may have impacted the communication between the collar and the VIT due to the limited time the collar and VIT were in close proximity to communicate via UHF and send a birth alert. Therefore, a reduction in the inactivity threshold to trigger the birth alerts is recommended although this could increase the false birth alert rate.

Tracking the VIT and the collared cows after expulsion in the field was challenging. This was partly due to the terrain, vegetation and size of the paddock, but also the limited range, or strength of the VIT signal to reach the VHF tracker, a limitation also noted by Rice et al. [40]. The initiation of real-time tracking after receiving a birth alert may improve accuracy, applications, and benefit future research in this area. It is recommended that real-time tracking of cows after birth should record a geolocation every 15-30 min to maximize the likelihood of finding the travelling cow and calf. Therefore, improvements to the VIT signal strength could help with VIT retrieval and confirming VIT expulsion site, but this could be restricted by the feasible size and weight of the VIT.

Both birth alert systems had advantages and limitations in relation to the ease of use and ability to track calves at birth. An advantage of both systems was the provision of a geolocation for the birth site, which made initial VHF tracking more efficient by providing a starting point. For Brand 2, the calving location was only accessible via their software, which slowed the process, whereas Brand 1 provided a geolocation in the email and GSM message. However, the geolocation provided by 
both systems was for the GNSS collar and not the VIT; therefore, the VIT had to be tracked with the handheld VHF antenna. Nevertheless, VHF was not accurate nor practical to find the cows or the VIT and therefore alternative technologies are required. The accuracy of both birth alert systems trialed was low and therefore, these are not suitable for use in extensive systems or animals free roaming in large areas. The main reasons for this poor performance were: early expulsion and lack of suitability for long-term deployments ( $\geq 3$ months), time delay between VIT expelling and receiving the alert message, low range of communication of the VIT with the collar using UHF, difficult localization of the cows after calving using the VHF tracker, the size of the paddock and difficult terrain, the behavior of cows at calving time, keeping on the move after calving and abandoning the calving site quickly. In addition, cows calving within the seven-day calibration period after VIT insertion for Brand 1 also resulted in missed birth alerts. These issues must be addressed before the technology becomes a viable solution for research and perhaps commercial applications in extensive cattle operations. Potential solutions may range from changing the thresholds for the birth alert criteria for temperature and activity to improving the strength of the VHF and UHF communications of the VIT, improving the communication protocol to send the alerts to the cloud, or initiating real time GPS tracking once a birth alert was set off. Initiation of real time tracking at birth would provide regular ongoing geolocation updates on calving animals to enable more efficient access to newborn calves, although this would increase satellite data costs.

\section{Conclusions}

The present study did not support the hypothesis that birth alert devices could be used to remotely detect time and location of calving events in extensive beef cattle operations. Findings suggest that these systems are not suitable in this environment in their current form and require adjustments to their alert threshold criteria before being a valuable tool in detecting births under conditions experienced in remote northern Australia. The study identified several limitations of birth alerts which may help to adapt these technologies for more effective use under harsher climatic regions. Future research may also benefit from a larger number of animals and more rigorous visual surveillance of animals, which would have been beneficial in Trial 1. However, the challenge of remote and large-scale conditions remains, and adequate surveillance of animals in this environment may always be a challenge. Attaching GNSS collars to calves at birth may be a future direction of this research, as it would assist in finding calves after death, which would aid researchers in detecting reasons for calf mortality.

Author Contributions: Conceptualization, L.A.G.; Data curation, C.P., L.L. and L.A.G.; Formal analysis, C.P., L.L. and L.A.G.; Funding acquisition, L.A.G.; Investigation, C.P.; Methodology, L.A.G.; Project administration, L.A.G.; Resources, C.P., L.L. and L.A.G.; Software, L.L. and L.A.G.; Supervision, L.L. and L.A.G.; Validation, C.P., L.L. and L.A.G.; Visualization, C.P.; Writing-original draft, C.P.; Writing-review \& editing, L.L. and L.A.G. All authors have read and agreed to the published version of the manuscript.

Funding: Meat and Livestock Australia project number P.PSH.0817, the Commonwealth Government of Australia, and The University of Sydney.

Acknowledgments: We would like to gratefully acknowledge funding from Meat and Livestock Australia, the Commonwealth Government of Australia and The University of Sydney. Their support was pivotal in the success of completing this study. We would also like to thank the managers at Newry Station, Dave and Ellie Young, who have far surpassed our hopes in their enthusiasm, commitment and long-term dedication to this work, they are a credit to the livestock industry. Without their help and passion, this study would not have been possible. We would also like to thank Jasmine Boxsell and the team at Consolidated Pastoral Company for their hard work in making the logistics of this study possible. Jas was a critical part of the team and her insights were valued greatly.

Conflicts of Interest: The authors declare no conflict of interest. The funders had no role in the design of the study; in the collection, analyses, or interpretation of data; in the writing of the manuscript, or in the decision to publish the results.

\section{References}

1. Clutton-Brock, T.H. The Evolution of Parental Care; Princeton University Press: Princeton, NJ, USA, 2020. 
2. McGowan, M.; McCosker, K.; Fordyce, G.; Smith, D.; O’Rouke, P.; Perkins, N.; Barnes, T.; Marquart, L.; Jephcott, J.; Morton, J.; et al. Technical Synopsis: CashCow Findings Insights into the Productivity and Performance of Northern Breeding Herds; Meat and Livestock Australia: Sydney, Australia, 2015; ISBN 9781740363020.

3. Barbknecht, A.E.; Fairbanks, W.S.; Rogerson, J.D.; Maichak, E.J.; Scurlock, B.M.; Meadows, L.L. Elk parturition site selection at local and landscape scales. J. Wildl. Manage. 2011, 75, 646-654. [CrossRef]

4. Barbknecht, A.E.; Fairbanks, W.S.; Rogerson, J.D.; Maichak, E.J.; Meadows, L.L. Effectiveness of Vaginal-Implant Transmitters for Locating Elk Parturition Sites. J. Wildl. Manage. 2009, 73, 144-148. [CrossRef]

5. Refshauge, G.; Brien, F.D.; Hinch, G.N.; Van De Ven, R. Neonatal lamb mortality: Factors associated with the death of Australian lambs. Anim. Prod. Sci. 2016, 56, 726-735. [CrossRef]

6. Johnstone-Yellin, T.L.; Shipley, L.A.; Myers, W.L. Effectiveness of Vaginal Implant Transmitters for Locating Neonatal Mule Deer Fawns. Wildl. Soc. Bull. 2006, 34, 338-344. [CrossRef]

7. Mcgraw, A.M.; Terry, J.; Moen, R. Pre-parturition movement patterns and birth site characteristics of moose in northeast Minnesota. Alces 2000, 50, 93-103.

8. Martin, P.; Philips, P.; Leith, R.; Cabohe, T. Australian Beef: Financial Performance of Beef Cattle Producing Farms, 2010-2011 to 2012-13; ABARES: Canberra, Australia, 2013; ISBN 9781743231418.

9. Hunt, L.P.; Petty, S.; Cowley, R.; Fisher, A.; Ash, A.J.; MacDonald, N. Factors affecting the management of cattle grazing distribution in northern Australia: Preliminary observations on the effect of paddock size and water points. Rangel. J. 2007, 29, 169-179. [CrossRef]

10. Swanson, C.C.; Jenks, J.A.; DePerno, C.S.; Klaver, R.W.; Osborn, R.G.; Tardiff, J.A. Does the use of vaginal-implant transmitters affect neonate survival rate of white-tailed deer Odocoileus virginianus. Wildl. Biol. 2008, 14, 272-279. [CrossRef]

11. Bishop, C.J.; Anderson, C.R.; Walsh, D.P.; Bergman, E.J.; Kuechle, P.; Roth, J. Effectiveness of a redesigned vaginal implant transmitter in mule deer. J. Wildl. Manage. 2011, 75, 1797-1806. [CrossRef]

12. Bishop, C.J.; Freddy, D.J.; White, G.C.; Watkins, B.E.; Stephenson, T.R.; Wolfe, L.L. Using Vaginal Implant Transmitters to Aid in Capture of Mule Deer Neonates. J. Wildl. Manage. 2007, 71, 945-954. [CrossRef]

13. Seward, N.W.; Maehr, D.S.; Gassett, J.W.; Cox, J.J.; Larkin, J.L. Field searches versus vaginal implant transmitters for locating elk calves. Wildl. Soc. Bull. 2005, 33, 751-755. [CrossRef]

14. Grigg, J.L.; Wolfe, L.L.; Fox, K.A.; Killion, H.J.; Jennings-Gaines, J.; Miller, M.W.P.; Dreher, B. Assessing Timing and Causes of Neonatal Lamb Losses in a Bighorn Sheep (Ovis canadensis canadensis) Herd via Use of Vaginal Implant Transmitters. J. Wildl. Dis. 2017, 53, 596-601. [CrossRef] [PubMed]

15. Johnson, B.K.; Mccoy, T.; Kochanny, C.O.; Cook, R.C.; Journal, S.; Medicine, W.; Sep, N. Evaluation of Vaginal Implant Transmitters in Elk (Cervus elaphus nelsoni). J. Zoo Wildl. Med. 2006, 37, 301-305. [CrossRef] [PubMed]

16. Sakatani, M.; Sugano, T.; Higo, A.; Naotsuka, K.; Hojo, T.; Gessei, S.; Uehara, H.; Takenouchi, N. Vaginal temperature measurement by a wireless sensor for predicting the onset of calving in Japanese Black cows. Theriogenology 2018, 111. [CrossRef]

17. Calcante, A.; Tangorra, F.M.; Marchesi, G.; Lazzari, M. A GPS/GSM based birth alarm system for grazing cows. Comput. Electron. Agric. 2014, 100, 123-130. [CrossRef]

18. Bureau of Meteorology Daily maximum temperature. Available online: http://www.bom.gov.au/jsp/ncc/cdio/ weatherData/av?p_nccObsCode=122\&p_display_type=dailyDataFile\&p_startYear $=2018 \&$ p_c $=-864745 \&$ P_stn_num=002056 (accessed on 29 April 2020).

19. Cowley, T.; Oxley, T.; MacDonald, N.; Cameron, A.G.; Conradie, P.; Collier, C.; Norwood, D. 2010 Pastoral Industry Survey - Northern Territory Wide; Northern Territory Government: Darwin, Australia, 2010; ISBN 9780724547678.

20. Zoetis Inc CIDRßDevices (Cattle). Available online: https://www.zoetis.com.au/product-class-new/ reproduction/cidr-devices-_cattle_.aspx (accessed on 29 April 2020).

21. Berglund, B.; Philipsson, J.; Danell, Ö. External signs of preparation for calving and course of parturition in Swedish dairy cattle breeds. Anim. Reprod. Sci. 1987, 15, 61-79. [CrossRef]

22. Duncan, N.B.; Meyer, A.M. Locomotion behavior changes in peripartum beef cows and heifers. J. Anim. Sci. 2019, 97, 509-520. [CrossRef]

23. Simundic, A.M. Measures of Diagnostic Accuracy: Basic Definitions. Ejifcc 2009, 19, $203-211$. 
24. R Core Team R: A language and environment for statistical computing. Available online: http://www.rproject.org/ (accessed on 29 April 2020).

25. De Oliveira, C.C.; Alves, F.V.; de Almeida Martins, P.G.M.; Junior, N.K.; Alves, G.F.; de Almeida, R.G.; Mastelaro, A.P.; da Costa e Silva, E.V. Vaginal temperature as indicative of thermoregulatory response in Nellore heifers under different microclimatic conditions. PLoS ONE 2019, 14, 1-13. [CrossRef]

26. Smith, J.F.; Harner, J.P. Kansas Agricultural Experiment Station Research Reports Using vaginal temperature to evaluate heat stress in dairy cattle. Kansas Agricult. Experim. Stat. Res. Reports 2014. [CrossRef]

27. Polsky, L.B.; Madureira, A.M.L.; Filho, E.L.D.; Soriano, S.; Sica, A.F.; Vasconcelos, J.L.M.; Cerri, R.L.A. Association between ambient temperature and humidity, vaginal temperature, and automatic activity monitoring on induced estrus in lactating cows. J. Dairy Sci. 2017, 100, 8590-8601. [CrossRef]

28. Vickers, L.A.; Burfeind, O.; von Keyserlingk, M.A.G.; Veira, D.M.; Weary, D.M.; Heuwieser, W. Technical note: Comparison of rectal and vaginal temperatures in lactating dairy cows. J. Dairy Sci. 2010, 93, 5246-5251. [CrossRef] [PubMed]

29. Kranstauber, B.; Smolla, M.; Scharf, A.K. Move: Visualizing and Analyzing Animal Track Data, 2019, R package version 3.2.2. Available online: https://CRAN.R-project.org/package=move (accessed on 30 November 2020).

30. Ipsen, M. World's best practice in Lamb Survival in particular the first three days of life. A report for 2014. Animal Produc. Sci. 2014, 54. [CrossRef]

31. Newbolt, C.H.; Ditchkoff, S.S. Effects of Environmental Conditions on Performance of Vaginal Implant Transmitters. J. Wildl. Manag. 2009, 73, 303-305. [CrossRef]

32. Cooke, R.F.; Bohnert, D.W.; Reis, M.M.; Cappellozza, B.I. Wolf presence in the ranch of origin: Impacts on temperament and physiological responses of beef cattle following a simulated wolf encounter. J. Anim. Sci. 2013, 91, 5905-5911. [CrossRef]

33. Rudolph, J.; Bruckmaier, R.M.; Kasimanickam, R.; Steiner, A.; Kirchhofer, M.; Hüsler, J.; Hirsbrunner, G. Comparison of the effect of a CIDR-Select Synch versus a long-term CIDR based AI protocol on reproductive performance in multiparous dairy cows in Swiss dairy farms. Reprod. Biol. Endocrinol. 2011, 9, 151. [CrossRef]

34. Norman, S.; Swain, D.; Collop, T.; Loy, J.; Larsen, J. Remote Calf Alert-Technology Development; Meat and Livestock Australia: Sydney, Astralia, 2011; ISBN 9781741918878.

35. Tatman, N.M.; Ballard, W.B.; Wallace, M.C.; Haskell, S.P.; Paul, R.; Tatman, N.M.; Ballard, W.B.; Wallace, M.C.; Haskell, S.P.; Krausman, P.R.; et al. Evaluation of Use of Vaginal-Implant Transmitters in Mule Deer (Odocoileus Hemionus). Southwest. Nat. 2018, 56, 247-251. [CrossRef]

36. Zartman, D.L.; Hallford, D.M.; Tierney, L.A.; Hussain, M. Reproductive characteristics of Holstein heifers fitted with intravaginal temperature transmitters. Theriogenology 1983, 19, 541-554. [CrossRef]

37. LoRa Alliance. At Tchnical Overview of LoRa and LoRaWAN. Available online: https://www.lora-alliance. org/portals/0/documents/whitepapers/LoRaWAN101.pdf (accessed on 25 September 2020).

38. LLC, L. LPWAN. Available online: https://drive.google.com/file/d/0B9pc9NuQD0hnOXIWcTdmc0N1UzQ/ view (accessed on 25 September 2020).

39. Mccosker, K.D. Risk Factors affecting the reproductive outcome of beef breeding herds in North Australia. Ph.D. Thesis, School of Veterinary Science, University of Queensland, Brisbane, Australia, 2016.

40. Rice, C.G. Development of a system for remotely monitoring vaginal implant transmitters and fawn survival. Wildlife Biol. 2016, 22, 22-28. [CrossRef]

Publisher's Note: MDPI stays neutral with regard to jurisdictional claims in published maps and institutional affiliations.

(C) 2020 by the authors. Licensee MDPI, Basel, Switzerland. This article is an open access article distributed under the terms and conditions of the Creative Commons Attribution (CC BY) license (http://creativecommons.org/licenses/by/4.0/). 